\title{
PENGARUH MOTIVATIONAL INTERVIEWING DAN SENAM TERHADAP KUALITAS HIDUP PENDERITA DM TIPE 2 DI PUSKESMAS PATTINGALOANG
}

\section{THE INFLUENCE OF MOTIVATIONAL INTERVIEWING AND GYMNASTICS ON THE QUALITY OF LIFE OF PATIENTS WITH TYPE 2 DIABETES IN PATTINGALOANG HEALTH CENTER}

\author{
Uliadi Barrung Limbong ${ }^{1}$, Ridwan Amiruddin ${ }^{2}$, Ridwan Mochtar Thaha ${ }^{3}$ \\ ${ }^{1}$ Program Pascasarjana, Departemen Epidemiologi, Fakultas Kesehatan Masyarakat, Universitas \\ Hasanuddin \\ ${ }^{2}$ Departemen Epidemiologi, Fakultas Kesehatan Masyarakat, Universitas Hasanuddin \\ ${ }^{3}$ Departemen Promosi Kesehatan dan Ilmu Perilaku, Fakultas Kesehatan Masyarakat, Universitas \\ Hasanuddin
}

Alamat Korespondensi: Fakultas Kesehatan Masyarakat Universitas Hasanuddin Makassar, 90242 HP: +6285255797670, Email: adhyeleon86@ gmail.com

\begin{abstract}
Abstrak
DM tipe 2 merupakan suatu penyakit kronik yang tidak bisa disembuhkan secara total sehingga menyebabkan prevalensinya justru meningkat setiap tahunnya. Tujuan penelitian ini adalah untuk melihat pengaruh motivational interviewing dan senam terhadap kualitas hidup domain Hubungan Sosial dan Kondisi Lingkungan penderita DM tipe 2. Jenis penelitian yang dilakukan yaitu eksperimen semu dengan rancangan Non Randomized Control Group Pretest Posttest Design. Populasi adalah semua penderita diabetes melitus tipe 2 yang tercatat pada rekam medis di Puskesmas. Teknik pengambilan sampel menggunakan teknik exhaustive sampling dengan besar sampel sebanyak 60 orang. Analisis data secara univariat dan bivariat dengan menggunakan uji beda dua mean dependen. Analisis statistik menunjukkan bahwa ada pengaruh intervensi yang diberikan terhadap kualitas hidup penderita DM tipe 2, pada domain hubungan sosial terjadi peningkatan skor mean kelompok intervensi dari 9,4 menjadi 11,27 ( $\mathrm{p}=0,000$ ); domain kondisi lingkungan nilai rata - rata (mean) kelompok intervensi saat pretest sebesar 26,6 meningkat saat posttest menjadi 31,23 ( $p=0,000)$. Intervensi melalui motivational interviewing dan senam efektif dalam meningkatkan kualitas hidup domain hubungan sosial dan kondisi lingkungan penderita DM tipe 2.
\end{abstract}

Kata kunci : diabetes, domain, motivational interviewing, senam

\begin{abstract}
Type 2 diabetes is a chronic disease that cannot be completely cured, causing the prevalence to increase every year. The aim of this study was to see the influence of motivational interviewing and gymnastics on the quality of life in the domain of Social Relations and Environmental Conditions of type 2 diabetes mellitus patients. The type of research was a quasi-experimental study with a Non Randomized Control Group Pretest Posttest Design. The population was all patients with type 2 diabetes mellitus recorded in the medical records at the Community Health Center. The sampling uses exhaustive sampling technique with a sample size of 60 people. Data analysis was univariate and bivariate by using two different mean dependent tests. Statistical analysis showed that there was an influence of the intervention given to the quality of life of patients with type 2 diabetes, in the domain of social relations there was an increase in the mean score of the intervention group from 9.4 to $11.27(p=0.000)$; mean in domain of environmental condition of the intervention group at pretest was 26.6 increased to 31.23 at posttest $(p=0.000)$. The interventions through motivational interviewing and gymnastics were effective in improving the quality of life in the domain of the social relations and environmental conditions of Type 2 DM patients.
\end{abstract}

Keywords: diabetes, domain, motivational interviewing, gymnastics 


\section{PENDAHULUAN}

Diabetes merupakan penyakit yang berhubungan dengan gaya hidup seperti pola makan dan kebiasaan beraktifitas. Risiko ini akan semakin meningkat pada individu dengan hipertensi tidak terkontrol, kurang berolahraga/beraktifitas fisik dan tidak taat dengan diet serta memiliki pola hidup yang tidak sehat (Damayanti, 2015). Diabetes melitus telah menjadi penyebab kematian terbesar ke-6 di dunia. Di tahun 2015, sebanyak 1,58 juta kematian yang disebabkan langsung oleh diabetes (2,8\% dari semua kematian di dunia) dan setiap tahunnya sebanyak 1,6 juta kematian secara langsung dikaitkan dengan diabetes (WHO, 2017).

WHO (2016) menyebutkan bahwa pada tahun 2015, Indonesia menempati urutan ke-7 di dunia sebagai negara dengan prevalensi penderita diabetes melitus terbanyak setelah China, India, Amerika Serikat, Brazil, Rusia dan Meksiko. Diabetes dengan komplikasi merupakan penyebab kematian tertinggi ketiga di Indonesia. Data Riset Kesehatan Dasar (Riskesdas) tahun 2013 menunjukkan prevalensi diabetes melitus di Indonesia cukup tinggi, mengalami peningkatan dari $1,1 \%$ di tahun 2007 menjadi 2,4\% di tahun 2013 dari keseluruhan penduduk sebanyak 250 juta jiwa.

DM tipe 2 merupakan suatu penyakit kronik yang tidak bisa disembuhkan secara total sehingga menyebabkan prevalensinya justru meningkat setiap tahunnya (Buchair, 2015). Pada studi Kaidaliri et.al. (2013) ditemukan bahwa penderita diabetes umumnya memiliki kualitas hidup yang buruk dibandingkan dengan orang yang tanpa penyakit karena dapat menyebabkan terjadinya komplikasi apabila tidak dilakukan perawatan diabetes yang tepat.

Perawatan diabetes tidak hanya pada bagaimana pasien mengelola kesehatan mereka, tetapi juga adanya dukungan dari petugas kesehatan yang memberikan pendidikan manajemen diabetes, mengenai perubahan gaya hidup dalam pengelolaan penyakitnya. Tujuan dari perawatan diabetes ini tidak untuk menyembuhkan tetapi untuk meningkatkan status fungsional penderita, meminimalkan gejala komplikasi, memperpanjang hidup melalui pencegahan sekunder dan meningkatkan kualitas hidup (Buchair, 2015). Kualitas hidup penting untuk diteliti karena dengan mengetahui kualitas hidup seseorang dapat membantu petugas kesehatan untuk mengetahui keadaan kesehatan seseorang sehingga dapat menjadi arah atau patokan dalam menentukan intervensi yang harus diberikan sesuai dengan keadaan penderita (Yudianto et.al., 2008).

PERKENI (2011) menyampaikan bahwa pengelolaan DM terdiri atas empat pilar utama yaitu mencakup edukasi, terapi gizi, aktifitas fisik, dan intervensi farmakologis. Salah satu intervensi yang dapat digunakan untuk merubah perilaku penderita dengan memanfaatkan hubungan interpersonal adalah dengan pendekatan motivational interviewing (MI). Studi oleh Nugroho (2016) menunjukkan bahwa terdapat perbedaan antara kelompok yang diberikan motivational interviewing dengan kelompok kontrol, dimana terdapat beda yang signifikan dengan $\mathrm{p}<0,05$ pada ukuran HbA1C, sehingga intervensi tersebut mampu mempengaruhi kualitas hidup pasien DM. Penelitian oleh Miller, et.al. (2014) pada wanita obesitas Afro-Amerika yang menderita DM Tipe 2 menunjukkan bahwa intervensi nutrisi medis dengan pendekatan motivational interviewing terbukti dapat meningkatkan kontrol glikemik dan kepercayaan diri responden.

Pengelolaan DM melalui aktifitas fisik dapat dilakukan melalui latihan jasmani. Latihan jasmani secara teratur dapat menurunkan kadar gula darah. Latihan jasmani selain untuk menjaga kebugaran juga dapat menurunkan berat badan dan memperbaiki sensitivitas insulin, sehingga akan memperbaiki kendali glukosa darah. Latihan jasmani yang dianjurkan berupa latihan jasmani yang bersifat aerobik seperti jalan kaki, bersepeda santai, jogging, berenang, dan senam (Utomo dkk., 2012). Hasil studi Lara dan Atik (2016) menunjukkan bahwa faktor kebiasaan olahraga berhubungan dengan kualitas hidup lansia penderita DM tipe 2. Selain itu, studi Cross Sectional oleh Halaweh et al (2015) menemukan bahwa nilai dalam semua Health Related Quality of Life (HRQoL) secara signifikan lebih tinggi $(\mathrm{P}<0,05)$ pada kelompok yang beraktifitas fisik sedang dan tinggi dibandingkan dengan kelompok beraktifitas fisik rendah dan ada korelasi signifikan antara lima dimensi HRQoL dan tingkat aktifitas fisik $(\mathrm{p}<0,001)$.

Banyaknya jumlah penderita DM di wilayah kerja Puskesmas Pattingaloang, beratnya beban yang ditimbulkan oleh penyakit DM dan komplikasinya, hubungannya dengan kualitas hidup penderitanya, serta masih kurangnya studi/penelitian yang mengangkat tema tentang intervensi melalui konseling 
dengan pendekatan wawancara motivasi yang dikombinasikan dengan aktifitas fisik, menjadikan peneliti ingin meneliti tentang pengaruh motivational interviewing dan senam terhadap kualitas hidup domain hubungan sosial dan kondisi lingkungan penderita diabetes melitus tipe 2 di wilayah tersebut.

\section{BAHAN DAN METODE}

\section{Lokasi dan Rancangan Penelitian}

Penelitian ini dilaksanakan wilayah kerja Puskesmas Pattingaloang (kelompok intervensi) dan di wilayah kerja Puskesmas Tabaringan (kelompok kontrol), Kota Makassar. Jenis penelitian yang digunakan adalah Quasi Eksperiment (Eksperimen Semu) dengan bentuk Non Randomized Control Group Pretest Posttest Design.

\section{Populasi dan Sampel}

Populasi adalah seluruh penderita diabetes yang tinggal di wilayah kerja Puskesmas Pattingaloang dan Puskesmas Tabaringan, Kota Makassar tahun 2018. Besar sampel adalah sebanyak 60 orang yang ditentukan melalui teknik exhaustive sampling.

\section{Metode Pengumpulan Data}

Pengumpulan data diawali dengan data sekunder yaitu berupa data penderita DM tipe 2 yang tercatat pada rekam medis Puskesmas Pattingaloang dan Puskesmas Tabaringan. Kemudian pada saat pelaksanaan, data diperoleh melalui wawancara langsung dengan responden pada tahap pretest dan posttest menggunakan kuesioner Karakteristik Umum dan WHOQoL-BREF berbahasa Indonesia yang telah distandarisasi oleh WHO. Pada tahap intervensi, responden pada kelompok intervensi diberikan konseling motivational interviewing oleh konselor (petugas Puskesmas terlatih) dan mengikuti program senam oleh instruktur terlatih dari Puskesmas sedangkan kelompok kontrol akan dibagikan leaflet yang berisi pedoman hidup sehat penderita DM.

\section{Analisis Data}

Analisis data secara univariat dan bivariat. Analisis data univariat untuk melihat karakteristik responden yang disajikan dalam tabel distribusi frekuensi. Analisis bivariat untuk menggambarkan perbedaan antara variabel independen dan variabel dependen dengan menggunakan uji beda $\mathrm{T}$ (T-test) dengan batas kemaknaan (nilai alpha- $\alpha$ ) 5\%. Untuk melihat perbandingan nilai mean dua kelompok (dua sampel) berpasangan maka digunakan Uji Beda Dua Mean Dependen (uji t berpasangan).

\section{HASIL \\ Karakteristik Responden}

Tabel 1 menunjukkan karakteristik responden berdasarkan kelompok umur, jenis kelamin, pekerjaan, status pernikahan, riwayat keluarga dan rutin periksa darah. Berdasarkan karakteristik kelompok umur, baik pada kelompok intervensi maupun kontrol, paling banyak berada pada kelompok umur $46-55$ tahun dan 56 - 65 tahun yaitu untuk kelompok intervensi masing - masing sebesar 36,7\% (11 orang) pada kelompok umur 46 - 55 tahun dan 55 - 56 tahun dan kelompok kontrol sebesar $33,3 \%$ (10 orang) pada kedua kelompok umur tersebut. Berdasarkan jenis sebagian besar responden baik pada kelompok intervensi maupun kontrol adalah perempuan. Pada kelompok intervensi, dari total 30 orang responden, yang berjenis kelamin perempuan sebesar $80 \%$ (24 orang) sedangkan pada kelompok kontrol sebesar 63,3\% (19 orang). Dari segi pekerjaan menunjukkan bahwa paling banyak responden kelompok intervensi dan kontrol berprofesi sebagai ibu rumah tangga (IRT) yaitu dengan proporsi masing masing sebesar $60 \%$ (18 orang) untuk kelompok intervensi dan 46,7\% (14 orang) untuk kelompok kontrol. Berdasarkan riwayat keluarga pernah menderita DM, pada kelompok intervensi terdapat sebesar 33,3\% (10 orang) yang memiliki riwayat keluarga pernah menderita DM dan pada kelompok kontrol sebesar $30 \%$ (9 orang). Menurut status responden rutin memeriksakan gula darah, pada kelompok intervensi sebesar 3,3\% (1 orang) yang mengatakan tidak secara rutin memeriksakan gula darahnya ke pusat pelayanan kesehatan sedangkan pada kelompok kontrol sebanyak $23,3 \%$.

Tabel 2 memperlihatkan distribusi responden menurut nilai statistik berupa nilai minimum dan maksimum skor pretest dan posttest, nilai rata - rata (mean) dan standar deviasi. Nilai rata - rata (mean) pada domain Hubungan Sosial, untuk kelompok intervensi pada saat pretest sebesar 9,4 dengan standar deviasi 0,97 meningkat saat posttest menjadi 11,27 dengan standar deviasi 1,11. Skor terendah pada saat pretest adalah 7 dan tertinggi 11 sedangkan saat posttest skor terendah adalah 9 dan tertinggi 13. Hasil pada kelompok kontrol menunjukkan bahwa nilai mean domain Hubungan Sosial saat pretest adalah 10,4 dengan standar deviasi 1,43 menurun menjadi 9,9 dengan standar deviasi 1,45 . Skor terendah 
responden saat pretest adalah 8 dan tertinggi 13 sedangkan saat posttest skor terendah adalah 7 dan tertinggi 12. Nilai rata - rata (mean) pada domain Kondisi Lingkungan, untuk kelompok intervensi pada saat pretest sebesar 26,6 dengan standar deviasi 2,06 meningkat saat posttest menjadi 31,23 dengan standar deviasi 2,40. Skor terendah pada saat pretest adalah 23 dan tertinggi 31 sedangkan saat posttest skor terendah adalah 23 dan tertinggi 35. Hasil pada kelompok kontrol menunjukkan bahwa nilai mean domain Kondisi Lingkungan saat pretest adalah 28,87 dengan standar deviasi 3,18 meningkat menjadi 29,2 dengan standar deviasi 2,70. Skor terendah responden saat pretest adalah 23 dan tertinggi 37 sedangkan saat posttest skor terendah adalah 23 dan tertinggi 33.

Tabel 1. Karakteristik Responden

\begin{tabular}{lcccc}
\hline \multirow{2}{*}{ Karakteristik Responden } & \multicolumn{2}{c}{ Kelompok Intervensi } & \multicolumn{2}{c}{ Kelompok Kontrol } \\
\cline { 2 - 5 } & Frekuensi & \% & Frekuensi & \% \\
\hline Kelompok Umur & 1 & 3,3 & 0 & 0 \\
$26-35$ & 2 & 6,7 & 3 & 10 \\
$36-45$ & 11 & 36,7 & 10 & 33,3 \\
$46-55$ & 11 & 36,7 & 10 & 33,3 \\
$56-65$ & 5 & 16,7 & 7 & 23,3 \\
$>65$ & & & & 36,7 \\
Jenis Kelamin & 6 & 20 & 11 & 63,3 \\
Laki - Laki & 24 & 80 & 19 & \\
Perempuan & & & & 33,3 \\
Pekerjaan & 4 & 13,3 & 10 & 3,3 \\
PNS & 1 & 3,3 & 1 & 0 \\
Karyawan Swasta & 3 & 10 & 5 & 46,7 \\
Wiraswasta & 4 & 13,3 & 0 & \\
Petani/Nelayan & 18 & 60 & 14 & 70 \\
IRT & & & & \\
Riwayat Keluarga & 10 & 33,3 & 9 & 76,7 \\
Ada & 20 & 66,7 & 21 & 23,3 \\
Tidak Ada & & & & 100 \\
Rutin Periksa Darah & 29 & 96,7 & 23 & \\
Ya & 1 & 3,3 & 7 & 30 \\
Tidak & 30 & 100 & & \\
\hline Jumlah & & &
\end{tabular}

Sumber: Data Primer, 2018

Tabel 2. Distribusi Responden Menurut Nilai Statistik Domain Kualitas Hidup Hubungan Sosial dan Kondisi Lingkungan

\begin{tabular}{ccccc}
\hline \multirow{2}{*}{ Nilai Statistik } & \multicolumn{2}{c}{ Domain Hubungan Sosial } & \multicolumn{2}{c}{ Domain Kondisi Lingkungan } \\
\cline { 2 - 5 } & Pretest & Posttest & Pretest & Posttest \\
\hline Kelompok Intervensi & 7 & & & \\
Minimum & 11 & 13 & 23 & 23 \\
Maksimum & 9,4 & 11,27 & 26,6 & 35 \\
Mean & 0,97 & 1,11 & 2,06 & 2,40 \\
SD & & & & \\
Kelompok Kontrol & 8 & 7 & 23 & 23 \\
Minimum & 13 & 12 & 37 & 29,2 \\
Maksimum & 10,4 & 9,9 & 28,87 & 2,70 \\
Mean & 1,43 & 1,45 & 3,18 & 30 \\
SD & 30 & 30 & 30 & \\
\hline Jumlah & & & &
\end{tabular}

Sumber: Data Primer, 2018 
Tabel 3 menunjukkan perbedaan nilai mean pretest dan posttest domain Hubungan Sosial dari kualitas hidup kelompok intervensi dan kontrol. Hasil memperlihatkan adanya perbedaan diantara kedua kelompok, dimana pada domain Hubungan Sosial, nilai mean untuk kelompok intervensi mengalami peningkatan mean dari 9,4 saat pretest menjadi 11,27 saat posttest sedangkan kelompok kontrol menurun dari 10,40 saat pretest menjadi 9,9 saat posttest . Hasil uji statistik menunjukkan bahwa pada kelompok intervensi nilai $\mathrm{p}=0,0001(\mathrm{p}<0,05)$ yang berarti ada perbedaan nilai domain Hubungan Sosial responden pada kelompok intervensi sebelum dan setelah diberikan motivational interviewing dan senam . Pada kelompok kontrol, hasil uji statistik menunjukkan nilai $p$ $=0,070(\mathrm{p}>0,05)$ yang berarti bahwa tidak ada perbedaan nilai domain Hubungan Sosial pada kelompok kontrol saat pretest dan posttest . Besarnya perbedaan rata - rata skor domain hubungan sosial antara kelompok intervensi dan kontrol saat posttest adalah sebesar 1,37.

Tabel 4 menunjukkan perbedaan nilai mean pretest dan posttest untuk domain Kondisi Lingkungan yang memperlihatkan bahwa nilai mean kelompok intervensi meningkat dari 26,6 saat pretest menjadi 31,23 saat posttest sedangkan kelompok kontrol juga mengalami peningkatan dari 28,87 saat pretest menjadi 29,2 saat posttest. Hasil uji statistik menunjukkan bahwa pada kelompok intervensi nilai $\mathrm{p}=0,0001(\mathrm{p}<0,05)$ yang berarti ada perbedaan nilai domain Kondisi Lingkungan responden pada kelompok intervensi sebelum dan setelah diberikan motivational interviewing dan senam. Pada kelompok kontrol, hasil uji statistik menunjukkan nilai $\mathrm{p}=0,517(\mathrm{p}>0,05)$ yang berarti bahwa tidak ada perbedaan nilai domain Kondisi Lingkungan pada kelompok kontrol saat pretest dan posttest. Besarnya perbedaan rata - rata skor antara kelompok intervensi dan kontrol saat posttest adalah sebesar 2,03.

\section{PEMBAHASAN}

Hasil penelitian ini menujukkan bahwa pada variabel domain Hubungan Sosial terjadi peningkatan rata - rata skor (mean) saat pretest ke posttest pada kelompok intervensi setelah diberikan motivational interviewing dan senam. Hasil uji statistik menunjukkan nilai $\mathrm{p}<$ 0,05 , memperlihatkan adanya perbedaan yang signifikan pada nilai mean domain Hubungan Sosial antara kelompok intervensi dan kelompok kontrol yaitu sebesar 1,37 sehingga dapat disimpulkan bahwa ada pengaruh motivational interviewing dan senam terhadap Domain Hubungan Sosial penderita DM tipe 2.

Aspek yang dinilai pada domain Hubungan Sosial meliputi hubungan personal, dukungan sosial dan aktifitas seksual. Peningkatan skor pada domain ini menunjukkan adanya pengaruh positif pemberian program motivational interviewing dan senam terhadap aspek hubungan sosial dari kualitas hidup responden kelompok intervensi. Program yang diberikan telah mendorong responden untuk hidup lebih produktif, lebih membuka diri untuk membagi permasalahan hidupnya terkait penyakit yang diderita dan meningkatkan kemauan interaksi sosial terutama karena adanya kebersamaan di dalam kelompok konseling dan senam.

Hasil penelitian sejalan dengan studi oleh Huang, et.al (2016) pada penderita diabetes melitus tipe 2 di Taiwan yang menemukan bahwa kelompok eksperimen yang diberikan motivational interviewing melalui terapi peningkatan motivasi dan kognitif memperlihatkan peningkatan yang signifikan dalam hal kualitas hidup secara fisik dan mental setelah pemberian intervensi dibandingkan dengan kelompok kontrol yang sama sekali tidak ada perubahan sepanjang penelitian dilaksanakan.

Penelitian oleh Thiel (2016) di Kanada yang menunjukkan bahwa ada hubungan positif yang signifikan antara aktifitas fisik dengan skor Health Related Quality of Life pada dimensi fungsi fisik, vitalitas dan kesehatan secara umum dari penderita DM tipe 2. Hasil ini tidak sejalan dengan penelitian oleh Hayashino, Tsujii dan Ishii (2017) di Jepang, yang menyatakan bahwa tidak ada peningkatan skor yang signifikan pada domain Hubungan Sosial Diabetes Theraphy-Related Quality of Life (DTR-QOL) pada penderita diabetes dengan nilai $p=0,507(p>0,05)$. Selain itu, studi kuasi eksperimen oleh Buchair (2015) pada penderita diabetes melitus tipe 2 di Makassar mendapatkan hasil yang sama bahwa ada perbedaan yang signifikan pada rata - rata skor domain 3 (hubungan sosial) antara kelompok intervensi yang diberikan konseling dan kelompok kontrol yaitu sebesar 18,10 (nilai $\mathrm{p}=$ $0,000<0,05$ ).

Variabel domain Kondisi Lingkungan sesuai hasil penelitian, terjadi peningkatan rata - rata skor (mean) saat pretest ke posttest pada kelompok intervensi setelah diberikan 
kombinasi program motivational interviewing dan senam. Hasil uji statistik menunjukkan nilai $\mathrm{p}<0,05$, yang menegaskan bahwa ada perbedaan signifikan nilai mean antara kelompok intervensi dan kelompok kontrol yaitu sebesar 2,03 sehingga dapat disimpulkan bahwa ada pengaruh pemberian motivational interviewing dan senam terhadap domain Kondisi Lingkungan penderita DM tipe 2.

Aspek yang dinilai pada domain Kondisi Lingkungan meliputi kemampuan finansial, kebebasan, ketersediaan pelayanan kesehatan dan sosial, lingkungan rumah, lingkungan fisik dan transportasi. Peningkatan skor pada domain ini menunjukkan bahwa pelaksanaan program motivational interviewing dan senam secara langsung telah mengarahkan responden untuk membuat keputusan dalam hidup mereka agar dapat memanfaatkan kemampuan finansial mereka untuk usaha terbaik bagi kesehatan dan pemulihannya, tergerak untuk melakukan pemeriksaan kesehatan secara rutin meskipun harus mengorbankan waktu mereka untuk mengantri di Puskesmas dan peduli dengan lingkungan dimana mereka tinggal serta lebih peduli dengan kebersihan dan kesehatan lingkungan tempat tinggal mereka. Kepuasan terhadap pelayanan Puskesmas juga diakui responden sangat baik yang meningkatkan rasa percaya untuk rajin memeriksakan kesehatan mereka dan mengikuti program yang dianjurkan.

Studi oleh Buchair (2015) di Makassar menemukan bahwa konseling memberikan pengaruh positif terhadap domain 4 kualitas hidup penderita DM tipe 2 dimana terdapat perbedaan yang signifikan rata - rata skor domain 4 antara kelompok intervensi dan kelompok kontrol sebesar 9,55 dengan nilai $\mathrm{p}=$ 0,008 ( $\mathrm{p}<0,05$ ). Hasil penelitian Tristiana (2016) juga menunjukkan bahwa Intervensi melalui motivational interviewing efektif dalam meningkatkan manajemen diri (diantaranya area aktifitas, diet dan pengobatan) dan kontrol glikemik pada pasien diabetes mellitus tipe 2 .

Penelitian oleh Halaweh, et.al (2015) pada pasien diabetes berusia lanjut di Palestina menyatakan bahwa nilai dalam semua dimensi Health Related Quality of Life (HRQoL) secara signifikan lebih tinggi $(\mathrm{p}<0,05)$ pada kelompok yang beraktifitas fisik sedang dan tinggi dibandingkan dengan kelompok yang beraktifitas fisik rendah, dan juga ada korelasi signifikan antara lima dimensi dalam HRQoL dengan tingkat aktifitas fisik $(\mathrm{p}<0,001)$. Studi eksperimen oleh Carus, et.al. (2016) pada 43 orang pasien DM tipe 2 menemukan bahwa dua belas minggu latihan gabungan aerobik (olahraga) memberikan perbaikan yang cukup besar dalam perbaikan beberapa aspek HRQoL pada penderita diabetes terutama pada fungsi fisik $(+51 \%)$, vitalitas $(+21 \%)$ dan kesehatan mental $(+40 \%)$. Latihan gabungan yang dilakukan tersebut juga terbukti sangat efektif untuk meningkatkan kekuatan otot dan kontrol glikemik penderita DM tipe 2.

\section{KESIMPULAN DAN SARAN}

Kesimpulan hasil penelitian ini bahwa terjadi peningkatan nilai mean kualitas hidup pada domain Hubungan Sosial dan Kondisi Lingkungan penderita DM tipe 2 di Puskesmas Pattingaloang (kelompok intervensi) sebelum dan setelah diberikan program motivational interviewing dan senam. Ada pengaruh pemberian program motivational interviewing dan senam dalam peningkatan kualitas hidup penderita diabetes melitus tipe 2 pada domain hubungan sosial dan domain kondisi lingkungan. Diperlukan adanya konsistensi penderita DM tipe 2 dalam melaksanakan aktifitas fisik (senam) secara rutin berkesinambungan dibarengi dengan inovasi pengelolaan penderita DM melalui konseling yang efektif dari pihak Puskesmas. Puskesmas dan Dinas Kesehatan perlu menyusun perencanaan program pengaplikasian metode intervensi penatalaksanaan DM melalui konseling dengan pendekatan Motivational Interviewing yang dapat menjadi wadah bagi penderita DM tipe 2 dalam manajemen diri sendiri dan meningkatkan kemandirian untuk kualitas hidup yang lebih baik. Pengembangan studi dalam durasi dan jangka waktu yang lama perlu dilakukan di masa yang akan datang.

\section{DAFTAR PUSTAKA}

Buchair, Nur Hikmah. (2015). Pengaruh Konseling Home Care Terhadap Kualitas Hidup Penderita Diabetes Melitus Tipe 2 di Puskesmas Talise Kota Palu (Tesis). Makassar: Pascasarjana Universitas Hasanuddin.

Carus, Tomas P., Ortega Alonso A \& Pietilainen K.H. (2016). A Randomized Controlled Trial on The Effects of Combined Aerobic-Resistance Exercise on Muscle Strength and Fatigue, Glycemic Control and HealthRelated Quality of Life of Type 2 
Diabetes Patients. The Journal of Sports Medicine and Physical Fitness, 56(5):572 - 578.

Damayanti, Santi. (2015). Diabetes Mellitus \& Penatalaksanaan Keperawatan, Yogyakarta: Nuha Medika.

Halaweh, Hadeel., Carin Wilena., Anna Grimby - Ekman \& Ulla Svantesson. (2015). Physical Activity and Health - Related Quality of Life Among Community Dwelling Elderly. J Clin Med Res, 7(11), $845-852$.

Huang, Chiung-Yu., Hui-Ling Lai., Chun-I Chen \& Yung-Chuan Lu. (2016). Effects Of Motivational Enhancement Therapy Plus Cognitive Behaviour Therapy On Depressive Symptoms And Health-Related Quality Of Life In Adults With Type II Diabetes Mellitus: A Randomised Controlled Trial. Qual Life Res, 25: 1275 - 1283.

Yasuaki, Hayashino., Satoru Tsujii \& Hitoshi Ishii. (2017). Association Of Diabetes Therapy-Related Quality Of Life And Physical Activity Levels In Patients With Type 2 Diabetes Receiving Medication Therapy: The Diabetes Distress And Care Registry At Tenri (DDCRT 17). Acta Diabetologica.

Kaidaliri, Aliasgarf., Najafi Baharak \& Maryam Mirmalek Sani. (2013). Quality of Life in People With Diabetes: a Systematic Review of Studies in Iran. Journal of Diabetes and Metabolic Disorders, 12:54.

Lara, Aviana Gita \& Atik Choirul Hidajah. (2016). Hubungan Pendidikan, Kebiasaan Olahraga, Dan Pola Makan Dengan Kualitas Hidup Lansia Di Puskesmas Wonokromo Surabaya. Jurnal Promkes, 4(1), 56 - 69.

Miller, Stephania T., Veronica J. Oates., Malinda A. Brooks., Ayumi Shintani., Tebeb Gebretsadik \& Darlene M. Jenkins. (2014). Preliminary Efficacy of Group Medical Nutrition Therapy and Motivational Interviewing among Obese African American Women with Type 2 Diabetes: A Pilot Study. Journal of Obesity, 1 - 7.

Nugroho, Christianto. (2016). Implementasi Motivasi Terhadap Penurunan HBA1C Pada Pasien Diabetes Melitus (Literatur Riview). Jurnal AKP, 7(1), 62 - 67.
Perkumpulan Endokrinologi Indonesia (PERKENI). (2011). Konsensus Pengelolaan dan Pencegahan Diabetes Melitus Tipe 2 di Indonesia. Jakarta: PB. PERKENI.

Riskesdas. (2013). Riset Kesehatan Dasar. Jakarta: Badan Penelitian Pengembangan Kesehatan Kementerian Kesehatan RI.

Thiel, Danielle Marie. (2016). The Association of Physical Activity and Health-Related Quality of Life in Adults with Diabetes (Tesis). Kanada: Public Health University of Alberta.

Utomo, Ocbrivianita M., Mahalul Azam \& Dina Nur A. (2012). Pengaruh Senam Terhadap Kadar Gula Darah Penderita Diabetes. Unnes Jurnal of Public Health; 1(1), 36 - 40.

WHO. (2016). Global Report on Diabetes. Perancis: WHO Library Cataloguing in Publication Data.

WHO. (2017). Global Report on Diabetes. Perancis: WHO Library Cataloguing in Publication Data.

Yudianto, Kurniawan., Hana Rizmadewi \& Ida Maryati. (2008). Kualitas Hidup Penderita Diabetes Mellitus di Rumah Sakit Umum Daerah Cianjur. Jurnal Keperawatan Universitas Padjajaran; 10(18), $76-87$.

Keperawatan Ditinjau Dari Beban Kerja Perawat. Berita Ilmu Keperawatan ISSN 1979-2697, Vol. 2 No. 1, Maret 2009:7-12. FIK, UMS.

Profil Rsud Labuang Baji. (2016). Profil Rumah Sakit Umum Daerah Labuang Baji Makassar. 